\title{
RESEARCH ON LIQUID FORMING PROCESS OF NICKEL SUPERALLOYS THIN SHEET METALS
}

\begin{abstract}
The paper presents the study of drawability of thin sheet metals made of a nickel superalloy Inconel type. The manufacturing process of axisymmetric cup - cone and a closed section profile in the form of a circular tube were designed and analyzed. In both cases, working fluid-oil was used in place of the rigid tools. The process of forming liquid is currently the only alternative method for obtaining complex shapes, coatings, and especially if we do it with high-strength materials. In the case of nickel superalloys the search for efficient methods to manufacture of the shaped shell is one of the most considerable problems in aircraft industry [1-5]. However, the automotive industries have the same problem with so-called advanced high-strength steels (AHSS). Due to this, both industrial problems have been examined and the emphasis have been put on the process of liquid forming (hydroforming). The study includes physical tests and the corresponding numerical simulations performed, using the software Eta/Dynaform 5.9. Numerical analysis of the qualitative and quantitative forecasting enables the formability of materials with complex and unusual characteristics of the mechanical properties and forming technology. It has been found that only the computer aided design based on physical and numerical modeling, makes efficient plastic processing possible using a method of hydroforming. Drawability evaluation based on the determination of the mechanical properties of complex characteristics is an indispensable element of this design in the best practice of industrial manufacturing products made of thin sheet metals.

Keywords: drawability, local strain distribution measurements, forming limit curve, AutoGrid strain analyzer, thin sheet metals, nickel superalloys, Inconel 625, Inconel 718, hydroforming
\end{abstract}

\section{Introduction}

In the modern construction of cars and airplanes the thin sheet metals of high strength play a significant role. These charge materials are transformed into functional parts of such vehicles by plastic working methods, mainly stamping. Forming complex shapes require the use of flexible tools in place of the rigid ones. The most often used technology for final shape forming is hydroforming process. This technology uses working liquid (oil, water, etc.) under pressure to transform charge material into a drawpiece. Looking for the best functionality of charge materials, nickel superalloys have been considered. To manufacture and shape such uncommon charge (high strength, heat and creep resistant) requires a special procedure of forming process designed on the basis of drawability evaluation of charge

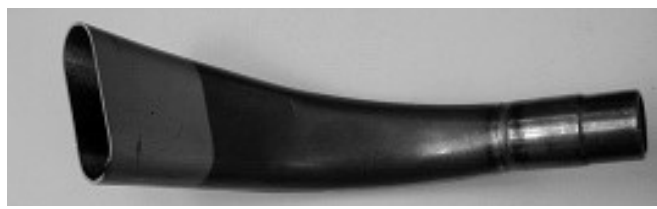

Fig. 1. A pressed element made of nickel superalloy by stamping and joining materials and numerical simulation of manufacturing process using FEM (finite elements method). An example of a pressed element from nickel superalloy requires the use of a special procedure shown in (Fig. 1).

\section{Nickel superalloys}

Superalloys or high-performance alloys have several characteristic parameters like: excellent mechanical strength, resistance to thermal creep deformation, good surface stability and resistance to corrosion or oxidation. The crystal structure is typically face-centered cubic austenitic. Among the superalloys there are: Hastelloy, Inconel, Waspaloy, Rene alloys, Haynes alloys, Incoloy, MP98T, TMS alloys, and CMSX single crystal alloys. Inconel 625 and Inconel 718 alloys in the group of nickel superalloys have been studied [6-11]. Both alloys have excellent strength (up to $820 \mathrm{MPa}$ ) and good high temperature strength (up to $700^{\circ} \mathrm{C}$ ). Inconels are precipitation-hardenable nickel-chromium alloys, containing large amount of iron, niobium and molybdenum. They also contain small amounts of titanium and aluminum. Chemical composition of studied Inconel alloys has been shown in (Tab. 1), whereas their mechanical properties in (Tab. 2).

\footnotetext{
SILESIAN UNIVERSITY OF TECHNOLOGY, INSTITUTE OF MATERIALS SCIENCE, KATOWICE, POLAND

Corresponding author: monika.hyrcza-michalska@polsl.pl
} 
TABLE 1

Chemical composition of studied Inconel alloys $[12,13]$

\begin{tabular}{|c|c|c|c|c|c|c|c|}
\hline \hline \multirow{2}{*}{ Alloy } & \multicolumn{7}{|c|}{ Element content, wt. \% } \\
\cline { 2 - 8 } & $\mathbf{N i}$ & $\mathbf{F e}$ & $\mathbf{C r}$ & $\mathbf{S i}$ & $\mathbf{M o}$ & $\mathbf{M n}$ & $\mathbf{C}$ \\
\hline $\begin{array}{c}\text { Inconel } \\
\mathbf{6 2 5}\end{array}$ & $\begin{array}{c}\mathrm{min} . \\
58.0\end{array}$ & 5.0 & $\begin{array}{c}20.0- \\
23.0\end{array}$ & 0.50 & $\begin{array}{c}8.0- \\
10.0\end{array}$ & 0.50 & 0.10 \\
\hline $\begin{array}{c}\text { Inconel } \\
\mathbf{7 1 8}\end{array}$ & $\begin{array}{c}50.0- \\
55.0\end{array}$ & \multirow{2}{*}{ Balanced } & $\begin{array}{c}17.0- \\
21.0\end{array}$ & 0.35 & $\begin{array}{c}2.80- \\
3.30\end{array}$ & 0.35 & 0.08 \\
\hline
\end{tabular}

TABLE 2

Measured mechanical properties of selected nickel superalloys

\begin{tabular}{|c|c|c|c|}
\hline \hline Alloy & $\begin{array}{c}\text { Thickness } \\
\text { [mm] }\end{array}$ & $\begin{array}{c}\text { UTS } \\
\text { [MPa] }\end{array}$ & $\begin{array}{c}\text { YS } \\
\text { [MPa] }\end{array}$ \\
\hline Inconel 718 & 0.9 & 896 & 494 \\
\hline Inconel 625 & 0.9 & 907 & 465 \\
\hline
\end{tabular}

In view of the unique strength properties, creep resistance at elevated temperatures and good formability of these alloys, they satisfy the need to produce lightweight thin-walled shell in the aircraft industry. However, the high strength Inconel alloys make it difficult to form it by rigid tools. The use of liquid, particularly oil, in the forming process (hydroforming) has been introduced. The possibility of using this technology is well developed for aluminum alloys and selected types of products [14]. But these are lightweight alloys with much less resistance. Hence, the sheet metal forming of stamping elements using liquid requires a special procedure for designing the manufacturing process of the items and that has been proposed by the author. This procedure is based on many years of experience in the assessment of drawability evaluation methods and modeling of manufacturing processes [1-5]. The basis of numerical modelling are experience and good FEM simulation practice acoording to $[15,16]$ and especially for Inconel superalloys [17-21].

\section{Drawability research of charge materials}

The special procedure of the designing of a forming process requires the evaluation of charge materials drawability. The following range of examinations have been carried out: stable tensile tests (results showed in Tabs. 2,3) and the evaluation of drawability: Erichsen cup forming test (results showed in Tab. 3) and forming limit curves determination using a spherical punch of $75 \mathrm{~mm}$ diameter and a set of samples (discs and undercuts discs of different width).

TABLE 3

Measured technological properties of selected nickel superalloys

\begin{tabular}{|c|c|c|c|}
\hline \hline Alloy & $\begin{array}{c}\text { Elongation, } \\
\mathbf{A}_{\mathbf{8 0}},[\%]\end{array}$ & $\begin{array}{c}\text { Langford } \\
\text { coeficient, } \\
\mathbf{R},[-]\end{array}$ & $\begin{array}{c}\text { Drawability } \\
\text { Erichsen coeficient, } \\
\text { IE }_{\mathbf{2 0}} \text {, [mm] }\end{array}$ \\
\hline Inconel 718 & 47 & 0.52 & 10.8 \\
\hline Inconel 625 & 44 & 0.49 & 11.8 \\
\hline
\end{tabular}

A modern AutoGrid local strain analyzer and a method of image analysis of the deformed parting grids (coordination nets with mesh parameter of $1 \mathrm{~mm}$ diameter) have been used for quantitative evaluation of drawability of Inconel alloy sheets. More details of Inconel alloys sheet metals forming limit curves determination are presented in previous publications [2-5]. Forming limit curves for tested Inconel alloys have been shown in (Fig. 2).

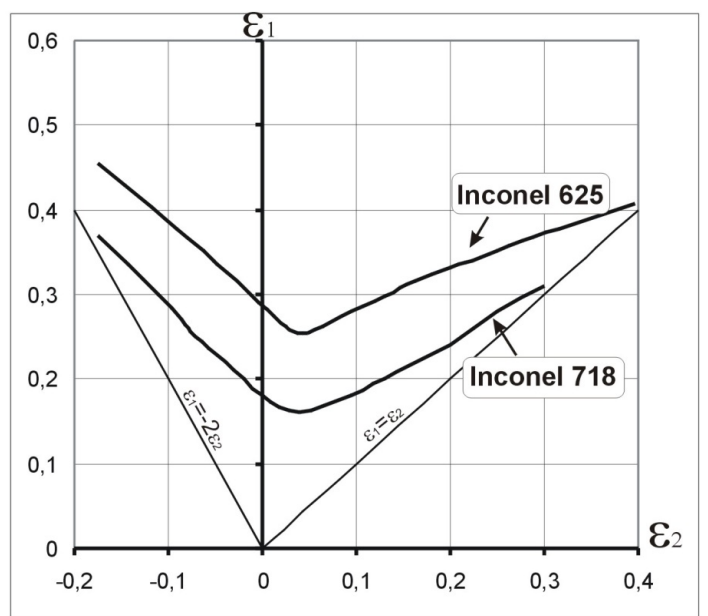

Fig. 2. Forming limit diagram for alloy Inconel 718 and Inconel 625, thickness $0.9 \mathrm{~mm}$

\section{Industrial hydroforming tests and numerical simulation of manufacturing process}

The implementation of industrial test pressing of the axial-symmetric product, applying liquid forming, was used for developing and extending a model of this process. Figure 3 shows the stamping machine used in industrial conditions on

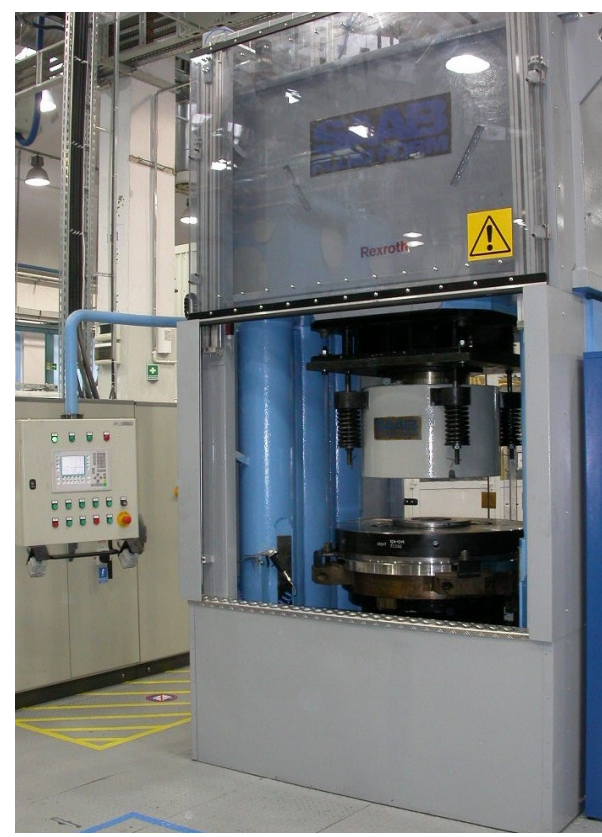

Fig. 3. Photograph of industrial hydraulic stamping machine for forming with the use of liquid 
Pratt \& Whitney Rzeszów S. A. in the process of hydroforming. Feedstock has been shown in (Fig. 4a) and a finished cone drawpiece has been shown in (Fig. 4b). In contrast, practicable methods of the cone preparation have been shown in (Fig. 5). a)

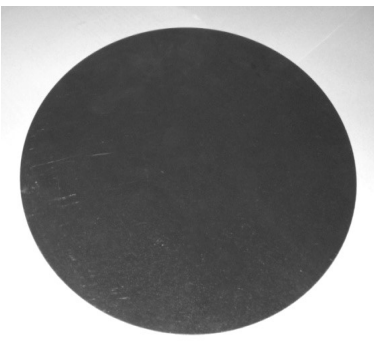

b)

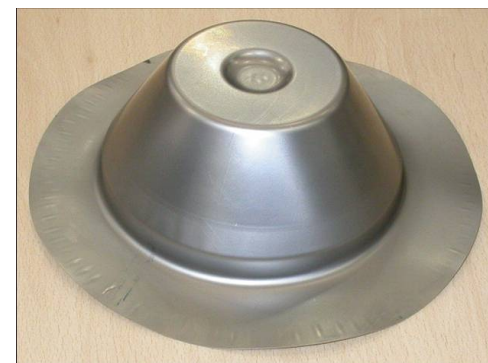

Fig. 4. Photography of cone cup and charge disc made of Inconel 625 alloy sheet, thickness $0,45 \mathrm{~mm}$ : a) charge disc od $215 \mathrm{~mm}$ diameter b) formed part - cone drawpiece a)

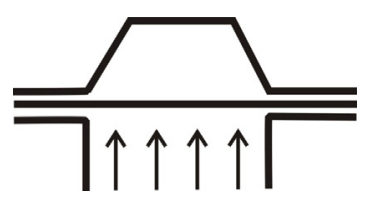

b)

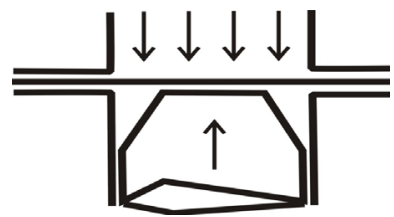

Fig. 5. The scheme of cone cup liquid forming methods: a) die method, b) punch method

Measurements of local strain distributions using the analyzer AutoGrid (Fig. 6) and coordination nets ( $2 \mathrm{~mm}$ size of square elements) applied to the sheet metals by electrochemical method gave a snapshot of the mechanical state during hydroforming of nickel superalloys sheet metals. Examples of measurement results have been shown in (Fig. 7).

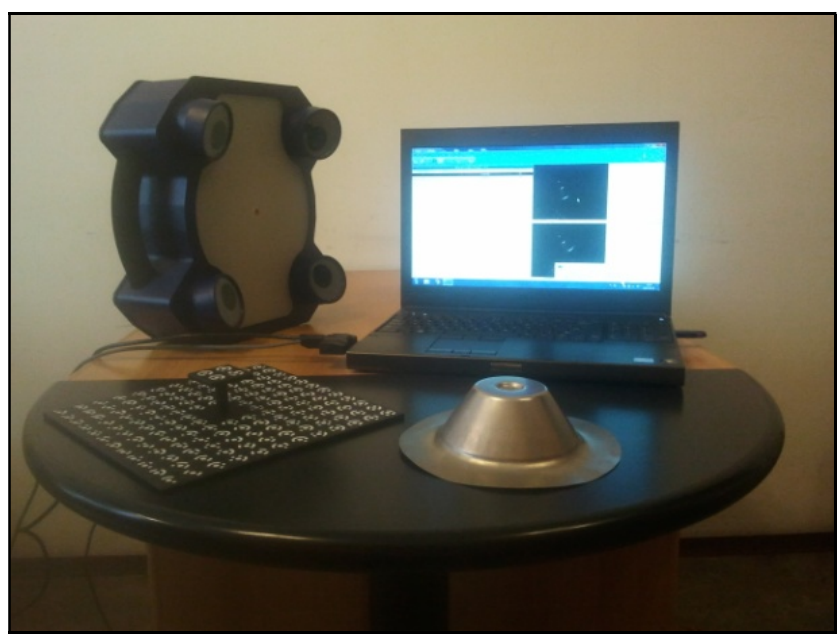

Fig. 6. Photography of movable strain analyzer AutoGrid in compact version used at industrial trials

The results of industrial tests were transferred to Eta/ Dynaform 5.9 software for the relevant preparation of manufac- turing process model using FEM. The modeled and simulated manufacturing process of cone drawpiece hydroforming and the example of the simulation result have been shown in (Fig. 8).
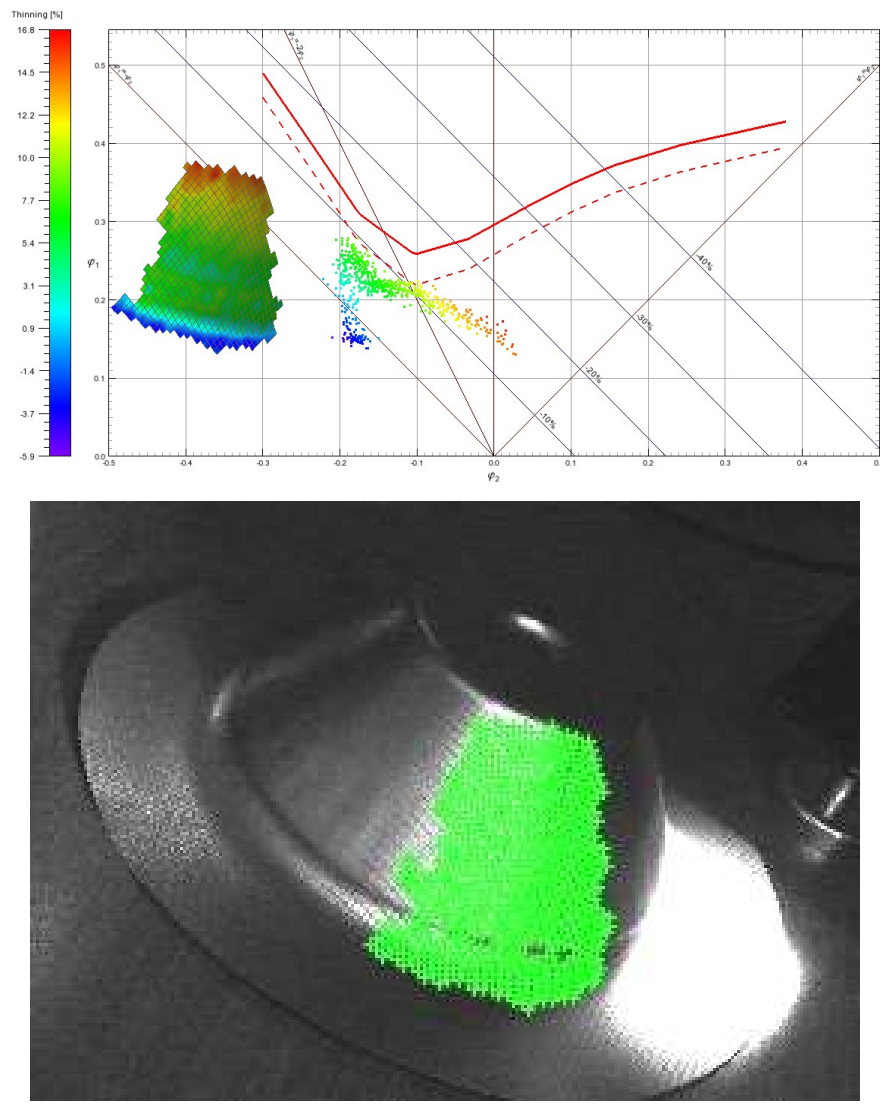

Fig. 7. The results of local strain distribution (thinning) measurements for a cone drawpiece after hydroforming industrial test

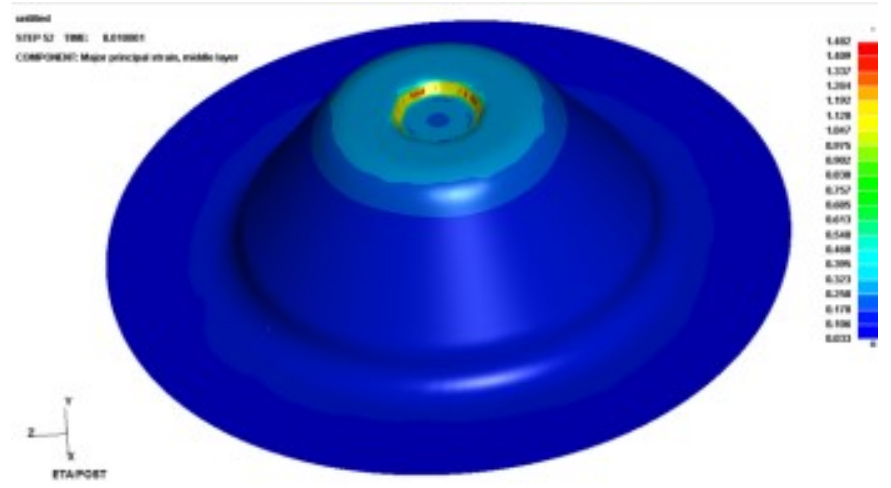

Fig. 8. An example of cone hydroforming simulation results from Eta/ Dynaform software

The above modeling cone drawpiece experiences were used to develop an alternative method of producing more complicated drawpieces (Fig. 1). Instead of pressing the two halves of the components and joining them by spawn, the use the tubular feedstock of a variable circular cross-section (conical tube) made of a sheet of Inconel 625 of $0.9 \mathrm{~mm}$ thick were suggested. The modeling results of the conical tube liquid forming have been shown in (Fig. 9). It is based on available in software data 
(material model No. 36*MAT_3-PARAMETER_BARLAT) and material characteristics Inconel alloys from uniaxial tensile tests, drawability tests and forming limit curves.

a)

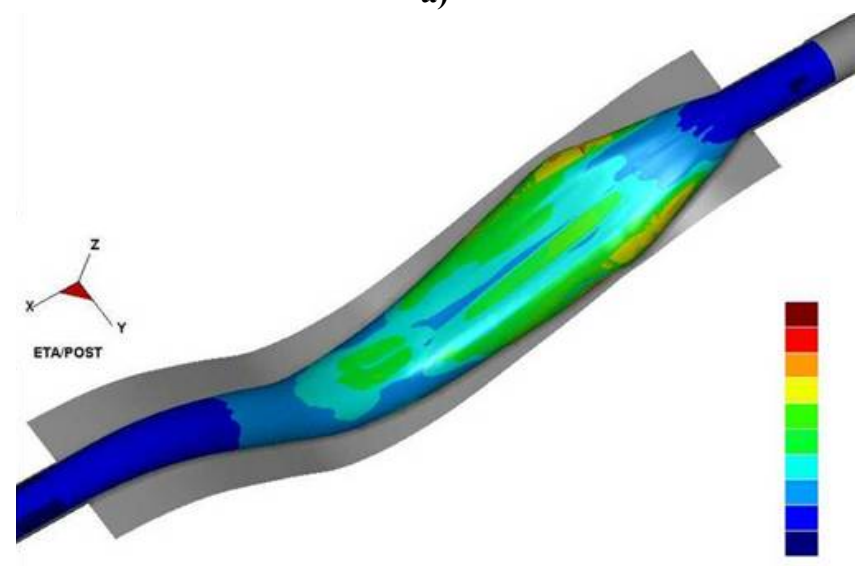

b)

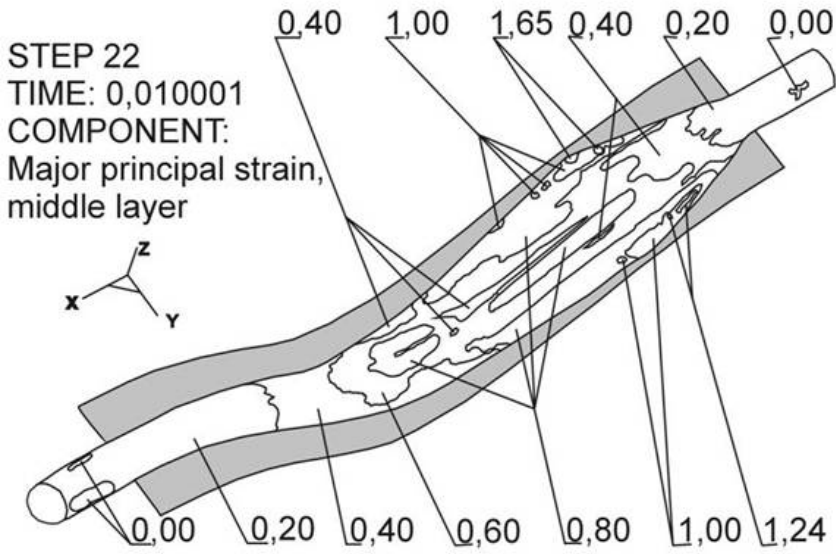

Fig. 9. The modeling results of the conical tube liquid forming using Eta/Dynaform software: a) view element after forming with color scale of local strain - qualitative analysis, b) quantitative analysis of local major strain distribution

\section{Summary and conclusions}

The carried out examinations fall within the scope of usefulness tests of special procedure of the designing of a forming process. It is based on charge materials drawability evaluation and numerical simulation of manufacturing process using FEM. This procedure could be successfully applied for high strength charge materials like nickel superalloys.

The more complicated shapes with thin wall elements can be produced in hydroforming processes due to a higher limiting formability without lowering the quality of a product. It is an alternative good solution for stamping using rigid tools. Introduc- ing software for modeling and numerical simulation, e.g. Eta/ Dynaform provides less time-consuming and effort-saving way to develop the process of preparing the hydroformed component. Furthermore, it allows obtaining the products of a complex geometry, high strength and good surface quality.

\section{Acknowledgements}

This paper was created with the financial support of Polish Ministry for Science and Higher Education under internal grant BK264/RM2/2016 for Institute of Metals Technology, Silesian University of Technology, Poland.

\section{REFERENCES}

[1] S.A. Asgari, M. Pereira, B.F. Rolfe, M. Dingle, P. D. Hodgson, J. Mater. Proc. Tech. 203 (1-3), 129-136 (2008).

[2] M. Hyrcza-Michalska, Sol. St. Phenom. 212, 259-262 (2014).

[3] M. Hyrcza-Michalska, Sol. St. Phenom. 246, 75-78 (2016).

[4] M. Hyrcza-Michalska, Hutnik - Wiadomości Hutnicze 79 (8), 595-599 (2013).

[5] M. Hyrcza-Michalska, Steel Res. Internat. Spec. edit. 2010 Metal Forming Conf. 81 (9), 817-820 (2010).

[6] Q. Huan, J. Mater. Eng. 8, 92-100 (2012).

[7] S. Azadian, L.-Y. Wei, R. Warren, Mater. Charact. 53, 7-16 (2004).

[8] V. Shankar, K.B.S. Rao, S.L. Mannan, J Nucl. Mater. 288, 222232 (2001).

[9] T. Drenger, J. Wiśniewski, S. Sosnowski, Ł. Nowacki, T. Gądek, Z. Ulatowski, Obróbka Plastyczna Metali 18, 15-22 (2007).

[10] A. Nowotnik, K. Kubiak, Hutnik - Wiadomości Hutnicze 75, 432-434 (2008).

[11] I. Dul, PS 81, 67-70 (2009).

[12] AMS 5599.

[13] AMS 5596.

[14] S. Novotny, P. Hein, J. Mat. Proc. Tech. 115, 65-69 (2001).

[15] A. Kocańda, H. Sadłowska, Arch. Civ. Mech.l Eng. 8 (3), 55-72 (2008).

[16] E. Onate, J. Rojek, M. Chiumenti, S.D. Idelsohn, F. Del Pin, R. Aubry, Comput. Methods Appl. Mech. Engrg. 195, 6750-6777 (2006).

[17] H-S. Jeong, M-Y. Ha, J-R. Cho, J. Prec. Eng. and Manuf. 13 (12), 2143-2148 (2012).

[18] J-T. Yoo, J-H. Yoon, H-S. Lee, S-K. Youn, J. Mech. Sci. Technol. 26 (7), 2101-2105 (2012).

[19] A.B. Sadat, M.Y. Reddy, Exp. Mech. 8, 282-288 (1992).

[20] A.B. Sadat, M.Y. Reddy, Exp. Mech.12, 343-348 (1993).

[21] N. Xiang, Z-J. Wang, J. Yi, H. Song, Int. J. Adv. Manuf. Technol. 12, (2016) (published on-line). 